\title{
O ENSINO DE LABORATÓRIO DE FÍSICA NA EDUCAÇÃO DO CAMPO E DA CIDADE
}

\author{
Maíra Lorena Paixão Barbosa ${ }^{1}$; Milton Souza Ribeiro Miltão ${ }^{2}$ \\ 1. Bolsista PIBIC/CNPq, Graduando em Física, Universidade Estadual de Feira de Santana, \\ e-mail:mairalorena12@hotmail.com \\ 2. Orientador, Departamento de Física, Universidade Estadual de Feira de Santana, e-mail: miltaaao@gmail.com
}

PALAVRAS-CHAVE: Instrumentação em Física, Educação do Campo, Educação da Cidade.

\section{INTRODUÇÃO}

A Física é a Ciência que estuda a natureza em seus mais diversos aspectos, buscando compreender a origem, evolução e estrutura da matéria e radiação do Universo. Atualmente, é difícil definir qual o campo de atuação da Física, pois ela aparece aplicada em diferentes campos do conhecimento que, à primeira vista e em uma visão não filosófica, parecem completamente descorrelacionados. Como ciência, faz uso do método científico, nas suas ênfases teórica e experimental. Geralmente, seus conceitos e principalmente suas teorias e leis gerais (Mecânica Clássica, Eletromagnetismo, Termodinâmica, Mecânica Relativística, Mecânica Quântica, e Mecânica Estatística), são aplicados na vida do ser humano com o intuito de desenvolver a capacidade de percepção e aumentar o seu conhecimento. Essas seis teorias e leis gerais formam a base de sustentação do Campo do Saber da Física e, nesse sentido permitem explorar a natureza em suas várias nuances, desde os menores sistemas físicos, as partículas elementares, até o maior, o Universo.

Foram estudados temas relacionados com a Instrumentação em Física, visando suas compreensões para propiciar, através da transposição didática, suas apresentações nas escolas do campo e da cidade. Pretendemos apresentar o estudo de tais temas, através de suas relações com o cotidiano, no interior da Bahia, tanto na zona rural quanto na zona urbana. Assim, torna-se necessária a compreensão do que é a Instrumentação em Física, que é a área da Física que lida com os aspectos experimentais, sem, no entanto, desconsiderar os aspectos teóricos, pois leva em conta que o ser humano, na sua construção do conhecimento, age através das ações do sentir, pensar e fazer. Nesse sentido, temos o objetivo de construir experimentos de baixo custo que serão utilizados pelos estudantes das Escolas Família Agrícolas (EFAs) e da cidade de Feira de Santana, utilizando as teorias físicas e as técnicas da Instrumentação Científica.

Com isso, levamos à comunidade dessas regiões uma ampla visão de todo esse conhecimento para possibilitar, através do diálogo sua construção. O objetivo principal é estudar o ensino de laboratório, com o intuito de construir e estimular tal conhecimento na região de Feira de Santana e no semiárido baiano. Essas regiões apresentam grande necessidade de desenvolvimento social e econômico, por serem áreas localizadas no interior do estado, o que a nosso ver justifica o presente plano de trabalho.

Vale frisar que esse trabalho já se encontra em andamento no sentido de que, alguns aspectos já foram explorados, inclusive com apresentação de resultados em 
eventos nas áreas da Física e da Educação. Esses aspectos referem-se à utilização da óptica, particularmente, do telescópio, nas Escolas Famílias Agrícolas (BARBOSA \& MILTÃO, 2013, 2014,2015a,2015b).

\section{MATERIAL E MÉTODOS OU METODOLOGIA}

A metodologia utilizada neste trabalho seguiu fazendo uma avaliação dos questionários e entrevistas aplicados durante as visitas a cada escola, em conjunto com uma revisão da bibliografia que dará suporte para a compreensão dos temas Instrumentação, Ensino de Laboratório, Filosofia da Física, e Etnofísica, a partir de textos clássicos que abordam o assunto; com isso poderemos utilizar materiais de baixo custo para a construção de experimentos. Paralelamente a este processo, estaremos discutindo através de reuniões de estudo os problemas básicos enfrentados por essas escolas tanto na zona rural, quanto na urbana, com o intuito de garantir uma perfeita assimilação de tais conteúdos, analisando de que forma poderemos contribuir com uma construção sólida de alguns conhecimentos ligados a área de Física para possibilitar a utilização dos experimentos de baixo custo voltados para o conhecimento da física.

\section{RESULTADOS E/OU DISCUSSÃO}

Como resultado temos: a Formação da candidata no tema da instrumentação cientifica, compreensão do significado de Pedagogia da Alternância, melhoria dos conhecimentos dos fenômenos físicos relacionados aos experimentos de baixo custo, construídos e apresentação de trabalhos em eventos tanto da área da física (ensino de física e instrumentação em física) quanto da área de educação.

\section{CONSIDERAÇÕES FINAIS}

Como resultado temos: A compreensão do significado de Pedagogia da Alternância, melhoria dos conhecimentos dos fenômenos físicos relacionados aos experimentos de baixo custo, construídos e apresentação de trabalhos em eventos tanto da área da física (ensino de física e instrumentação em física) quanto da área de educação.

\section{REFERÊNCIAS}

ANACLETO, B. S. Etnofísica na lavoura de arroz. Dissertação de Mestrado. Programa de Pós-graduação em Ensino de Ciência e Matemática da Universidade Luterana do Brasil. 2007.

ARROYO, Miguel; CALDART, Roseli S.; MOLINA, Mônica Castagna (Org.). Por uma educação do campo. Petrópolis, RJ: Vozes, 2004. 
BARBOSA, M.L.P.; MILTÃO, M.S.R. Alguns aspectos da Educação do Campo, Pedagogia da Alternância e Ciências Físicas nas EFAs do Semiárido. Anais do XXI Simpósio Nacional de Ensino de Física, 2015a.

BARBOSA, M.L.P.; MILTÃO, M.S.R. Educação do Campo, Pedagogia da Alternância e Ciências Físicas nas EFAs do Semiárido. Anais dos XXXII Encontro de Físicos do Norte e Nordeste 2014.

BARBOSA, M.L.P.; MILTÃO, M.S.R. O estudo da óptica e da fluorescência voltados para a Pedagogia da Alternância nas EFAs. Anais do XXX Encontro de Físicos do Norte e Nordeste. 2015b.

BARBOSA, M.L.P.; MILTÃO, M.S.R. O estudo da óptica e do telescópio voltado para a Pedagogia da Alternância nas EFAs. Anais dos XXI Encontro de Pesquisa Educacional do Norte e Nordeste. 2013.

CAVALCANTE, Ludmila Oliveira Holanda. A escola família agrícola - quais caminhos em que direção? In: Caderno Multidisciplinar - Educação e Contexto do Semi-Árido. Rede de Educação do Semi-árido. Juazeiro, Bahia. 2006.

DEMO, Pedro. Pesquisa Participante - saber pensar e intervir juntos. Série Pesquisa em Educação. Brasília, DF. Liber Livro Editora LTDA.2004.

FREIRE, Paulo. Pedagogia do Oprimido. $17^{\circ}$ Ed. Rio de Janeiro; Paz e Terra, 1987;

GIANOTTEN Vera e WIT, Ton de. Pesquisa Participante em um contexto de economia camponesa. In: Repensando a Pesquisa Participante. BRANDÃO, C. R. (Org.). São Paulo. Editora Brasiliense. 2000.

GUERRA, Andreia; REIS, Jose Claudio; BRAGA, Marco. Uma Abordagem HistóricoFilosófica para o Eletromagnetismo no Ensino Médio. Cad. Bras. Ens. Fís., v. 21, n. 2: p. 224-248, ago. 2004.

KLEIBER, J. Compêndio de Física, 2a ed. Globo, Porto Alegre - RGS, 1935.

LOPES, J Bernardino. Aprender e Ensinar Física. Lisboa. Fundação Calouste Gulbenkian, 2004.

MILTÃO, M. S. R.; SANTANA, C. S. C.; BARRETO, A. L. V.; CARDOSO, G. K. R. O Ensino de Física e a Educação do Campo: uma relação que precisa ser efetivada. In: Álvaro Santos Alves; José Carlos Oliveira de Jesus; Gustavo Rodrigues Rocha. (Org.). Ensino de Física: reflexões, abordagens e práticas. 1ed. São Paulo: Livraria da Física, 2012, v. 1, p. 169-198.

MILTÃO, M. S. R.; SIMÕES, Maria Tereza Moraes; SERRA, Denise Simões; SOUSA, Tânia Cristina R. Considerações Gerais sobre o Uso dos Livros Didáticos a partir da Experiência de Professores em Sala de Aula no Nível Médio. Caderno de Física da UEFS, v. 04, p. 51-80, 2006.

MILTÃO, M. S. R.; SIMÕES, Maria Tereza Moraes; SERRA, Denise Simões; SOUSA, Tânia Cristina R. O Uso do Livro Didático na Visão dos Professores da Escola Secundária: considerações gerais. Sitientibus Série Ciências Físicas, v. 02, p. 68-84, 2006.

MILTÃO, M. S. R.; FREITAS, D. S.; MOTTA, Durval Eusíquio de Miranda. O ensino de laboratório de física na UEFS: considerações teórico-pedagógicas. Sitientibus (UEFS), Feira de Santana, v. 16, p. 123-130, 1997.

MILTÃO, M. S. R.; FREITAS, D. S.; MOTTA, Durval Eusíquio de Miranda. A problemática do ensino de laboratório de física na UEFS. Revista Brasileira de Ensino de Física, v. 19, p. 444-447, 1997.

PAIVA, Vanilda. História da Educação popular no Brasil: educação popular e educação de adultos. 6. ed. São Paulo: Loyola, 2003. 